\title{
Fetomaternal outcome in operative vaginal delivery
}

\author{
Jeyamani B., Nashreen Dhasleema A.*
}

Department of Obstetrics and Gynaecology, Vinayaka Mission's Kirupananda Variyar Medical College and Hospitals, Salem, Tamil Nadu, India

Received: 29 September 2021

Accepted: 25 October 2021

\section{*Correspondence:}

Dr. Nashreen Dhasleema A., E-mail: nasthaslee95@gmail.com

Copyright: (C) the author(s), publisher and licensee Medip Academy. This is an open-access article distributed under the terms of the Creative Commons Attribution Non-Commercial License, which permits unrestricted non-commercial use, distribution, and reproduction in any medium, provided the original work is properly cited.

\section{ABSTRACT}

Background: Operative vaginal deliveries (OVD) were performed with the help of vacuum or forceps in the second stage of labor when mother and foetus condition is threatening. A successful assisted vaginal delivery avoids caesarean section and its associated morbidity and implications for future pregnancy. The aim of the study was to assess the maternal and neonatal outcome of vacuum and forceps assisted vaginal deliveries.

Methods: It was a retrospective comparative cross sectional study done in VMKVMCH, Salem in obstetrics and gynecology department, from the period of April to June 2021. All the mothers delivered by operative vaginal delivery were included. Mothers with multiple pregnancies, preterm and breech presentation were excluded. Data collected using patients information sheet and analysis was done using SPSS 23. P value $<0.05$ was considered significant.

Results: The most common age group was 21-25 years of age in both groups and most commonly used in primigravida. The most common indication for forceps assisted delivery in our study was the prolonged second stage labour and in vacuum delivery was poor maternal effort. In our study, common complication noted was extended episiotomy followed by perineal tear in forceps group and vice versa in vacuum group. Cephalhematoma was found to be more common in vacuum and scalp and instrumental injuries were more common in forceps assisted vaginal deliveries.

Conclusions: Operative vaginal deliveries helps in improving both maternal and foetal outcomes and reduces the caesarean delivery rate and vacuum significantly reduces maternal trauma than forceps. No difference noted in neonatal outcome.

Keywords: Operative vaginal delivery, Instrumental delivery, Vacuum, Forceps, Assisted vaginal delivery

\section{INTRODUCTION}

Instrumental vaginal delivery is a age old practice which is used to fasten the vaginal delivery or to prevent unnecessary caesarean delivery. It is done by applying obstetric forceps or vacuum device. They are performed when any event threatens the mother or foetus and it is a second stage labour intervention. ${ }^{1-3}$ The choice is made mainly based on two things one is tradition and the other is training. ${ }^{4}$ In Europe and Asia, vacuum extraction is used much whereas in North America forceps is used much. ${ }^{5-7}$ Vacuum gained popularity in recent days due to the reduced risk of injury to neonates and the new designs of vacuum cups. ${ }^{8}$ In 1849, it was James Young Simpson who was the first to use traction to deliver a baby. Later in 1953, Malmstrom modified it. Obstetric forceps has a history from the seventh century from the time of Chambelain family.

The most common indications for instrumental delivery are prolonged second stage labour, any immediate or potential fetal compromise and for the sake of mother's benefit shortening the second stage of labour. ${ }^{9}$ Some of the absolute contraindications are malpresentation, unengaged fetal head, incompletely dilated cervix, cephalopelvic disproportion and fetal clotting disorder. Nowadays, 
modern obstetrics practice has witnessed an increase in caesarean section all over the world. Vacuum extraction and forceps offers the option for safe delivery for the mother and the clinician. Assisted vaginal delivery avoids caesarean section, its uterine scars and its implications on future pregnancy. The success and safety of the procedure depends on the operators skill, its timing and its justified indications.

Vacuum and forceps have been compared in many studies. ${ }^{10,11}$ Many studies suggested different maternal and neonatal outcomes between the two methods. But when compared to normal spontaneous vaginal deliveries, assisted vaginal deliveries were associated with maternal and neonatal injury and also poor maternal and neonatal outcome, especially with less trained obstetricians. It had also been reported that when compared to forceps delivery, maternal injury was less frequent in vacuum. ${ }^{15}$ This study was done to assess the maternal and foetal outcome of vacuum and forceps assisted vaginal deliveries.

\section{Objective}

The objective was to assess maternal and foetal outcome of vacuum and forceps assisted vaginal deliveries.

\section{METHODS}

\section{Study area}

The study was done in VMKV medical college and hospital, Salem, Tamil Nadu in obstetrics and gynaecology department, for a period of 3 months from April 2021 to June 2021.

\section{Study type}

The study was a retrospective comparative cross-sectional study.

\section{Sample size}

Around 50 postnatal mothers delivered by instrumental delivery were included retrospectively during the study period.

\section{Inclusion criteria}

All those antenatal mothers with singleton pregnancy, completed 37 weeks of gestation with vertex presentation, delivered by instrumental vaginal delivery were included.

\section{Exclusion criteria}

Multiple pregnancy, preterm ( $<37$ weeks of gestation), breech presentation (for forceps in aftercoming head) patients were excluded.

\section{Instruments used}

For forceps delivery, Wrigley forceps which was short curved outlet forceps was used.

Vacuum extraction was done with silastic $40 \mathrm{~mm}$ and 60 $\mathrm{mm}$ cups. The negative pressure was applied up to 0.6 $\mathrm{kg} / \mathrm{cm}^{2}$.

\section{Data collection}

After obtaining institutional ethical committee clearance, data was collected like their baseline characteristics like name, age, parity, gestational weeks, risk factors were taken from the patient information sheet. Maternal outcome was analysed in terms of episiotomy extensions, postpartum haemorrhage, perineal tear and cervical tear. Neonatal outcome was analysed in terms of APGAR score at 1 minute and 5 minutes, NICU admissions and neonatal complications like cephalhematoma, convulsions, hyperbilirubinemia, subconjunctival haemorrhage were analysed.

\section{Statistical analysis}

Once the data was collected, it was entered in MS excel Windows 10. Statistical analysis was done by SPSS 23. Continuous variable was expressed in terms of Mean and Standard deviation. Categorical variables was expressed in terms of numbers (percentages). Association between categorical variables were found using Chi square test whereas association between continuous variables were found by ANOVA test. $\mathrm{P}$ value $<0.05$ was considered as statistically significant.

\section{RESULTS}

In our study population, the most common age group was 21-25 years in both age group (vacuum $=48 \%$, forceps $=52 \%$ ) followed by 26-30 years of age (vacuum $=32 \%$, forceps $=24 \%$ ). Instrumental deliveries were common in primigravida (vacuum $=56 \%$, forceps $=60 \%$ ). The instrumental deliveries were common in patients with 37-40 weeks (vacuum $=84 \%$, forceps $=88 \%$ ) followed by less than 37 weeks in vacuum.

The most common indication for forceps assisted delivery in our study was the prolonged second stage of labour 9 (36\%) followed by fetal distress $8(32 \%)$ which in turn followed by poor maternal effort $6(24 \%)$. In our study, the most common indications for use of vacuum was poor maternal effort $13(52 \%)$ followed by prolonged second stage of labour $9(36 \%)$ followed by fetal distress $1(4 \%)$.

The maternal morbidity was significantly less in vacuum than forceps groups particularly episiotomy extension $(p=0.04)$ and length of hospital stay $(p<0.001)$ were main morbidity which were significant. 
Table 1: Demographic profile of the study participants $(n=50)$.

\begin{tabular}{|lll|}
\hline Parameters & \multicolumn{1}{c|}{ Vacuum } & Forceps \\
\hline Maternal age (in years) & $\mathrm{N}(\%)$ & $\mathrm{N}(\%)$ \\
\hline$<20$ & $2(8)$ & $4(16)$ \\
\hline $21-25$ & $12(48)$ & $13(52)$ \\
\hline $26-30$ & $8(32)$ & $6(24)$ \\
\hline $31-35$ & $2(8)$ & $2(8)$ \\
\hline$>35$ & $1(4)$ & - \\
\hline Gestational age (in weeks) & & $3(12)$ \\
\hline$<37$ & $3(8)$ & $22(88)$ \\
\hline $37-40$ & $21(84)$ & \\
\hline$>40$ & $2(8)$ & $15(60)$ \\
\hline Parity & $14(56)$ & $10(40)$ \\
\hline Primigravida & $11(44)$ & \\
\hline Multigravida & & \\
\hline
\end{tabular}

Table 2: Indications of instrumental vaginal delivery.

\begin{tabular}{|llll|}
\hline Indications & Vacuum $(\mathbf{n}=\mathbf{2 5})$ & Forceps $(\mathbf{n}=\mathbf{2 5})$ & P value \\
\hline $\begin{array}{l}\text { Prolonged second stage of } \\
\text { labour }\end{array}$ & $\mathrm{N}(\%)$ & $\mathrm{N}(\%)$ & 0.7 \\
\hline Poor maternal effort & $9(36)$ & $9(36)$ & $0.02 / 4$ \\
\hline Fetal distress & $13(52)$ & $6(24)$ & $0.002 / 4$ \\
\hline Anaemia & $1(4)$ & $8(32)$ & $0.5 />0.99$ \\
\hline Preeclampsia & $1(4)$ & $1(4)$ & $0.5 />0.99$ \\
\hline
\end{tabular}

Table 3: Maternal morbidity in instrumental delivery.

\begin{tabular}{|llll|}
\hline Indications & Vacuum $(\mathbf{n}=\mathbf{2 5})$ & Forceps $(\mathbf{n}=\mathbf{2 5})$ & P value \\
\hline Episiotomy & $\mathrm{N}(\%)$ & $\mathrm{N}(\%)$ & NS \\
\hline Episiotomy extension & $25(100)$ & $25(100)$ & 0.04 \\
\hline Cervical tear & $6(24)$ & $16(64)$ & 0.55 \\
\hline $\begin{array}{l}\text { First and second degree } \\
\text { perineal tear }\end{array}$ & $2(8)$ & $1(4)$ & 0.38 \\
\hline $\begin{array}{l}\text { Third and fourth degree } \\
\text { perineal tear }\end{array}$ & $8(32)$ & $11(44)$ & 0.12 \\
\hline Postpartum haemorrhage & $1(4)$ & $6(24)$ & 0.55 \\
\hline Blood transfusion needed & $5(20)$ & $2(8)$ & 0.44 \\
\hline $\begin{array}{l}\text { Length of hospital stay } \\
\text { (in hrs) }\end{array}$ & 48 & $3(12)$ & $<0.001$ \\
\hline
\end{tabular}

Table 4: Neonatal morbidity and mortality.

\begin{tabular}{|c|c|c|c|}
\hline \multirow{2}{*}{ Indications } & Vacuum (n=25) & Forceps $(\mathrm{n}=\mathbf{2 5})$ & \multirow{2}{*}{$P$ value } \\
\hline & $\mathrm{N}(\%)$ & $\mathrm{N}(\%)$ & \\
\hline Cephalhematoma & $12(48)$ & $3(12)$ & $<0.005$ \\
\hline Subconjunctival haemorrhage & $4(16)$ & - & NS \\
\hline Scalp injuries & $2(8)$ & $9(36)$ & $<0.016$ \\
\hline Instrumental abrasions & $2(8)$ & $19(76)$ & $<0.0001$ \\
\hline Neonatal convulsions & $3(12)$ & $4(16)$ & 0.68 \\
\hline Neonatal hyperbilirubinemia & $16(64)$ & $3(12)$ & $<0.0001$ \\
\hline NICU admission & $10(40)$ & $12(48)$ & 0.56 \\
\hline
\end{tabular}


Table 5: Neonatal outcome.

\begin{tabular}{|lll|}
\hline Variables & Vacuum N $(\%)$ & Forceps $\mathbf{N}(\%)$ \\
\hline Birthweight (in kgs) & & \\
\hline$<2$ & $1(4)$ & $2(8)$ \\
\hline $2-2.5$ & $5(20)$ & $4(16)$ \\
\hline $2.6-3$ & $10(40)$ & $9(36)$ \\
\hline $3-3.5$ & $7(28)$ & $5(20)$ \\
\hline$>3.5$ & $2(8)$ & $5(20)$ \\
\hline APGAR at 1 minute & & \\
\hline$<3$ & $1(4)$ & $2(8)$ \\
\hline $4-7$ & $6(24)$ & $6(24)$ \\
\hline $7-10$ & $18(72)$ & $17(68)$ \\
\hline APGAR at 5 minutes & & \\
\hline$<3$ & - & - \\
\hline $4-7$ & - & $1(4)$ \\
\hline $7-10$ & $25(100)$ & $24(96)$ \\
\hline
\end{tabular}

The risk of neonatal morbidity was similar between the babies delivered by vacuum and forceps in our study population. Cephalhematoma was common in vacuum 12 (48\%) delivered babies compared to forceps 3 (12\%) and it was statistically significant $(\mathrm{p} \leq 0.005)$ followed by neonatal hyperbilirubinemia $16(64 \%)$ which was also statistically significant. Scalp injuries 9 (36\%) and instrumental abrasions $19(76 \%)$ were more in forceps delivery. The difference between them was also statistically significant. The NICU admission was more in the forceps delivery $12(48 \%)$ followed by vacuum delivery $10(40 \%)$, But the difference was statistically not significant $(\mathrm{p}=0.56)$.

The most common birthweight was $2.6-3 \mathrm{~kg}$ (vacuum 10 (40\%), forceps $9(36 \%)$ ) followed by $3-3.5 \mathrm{~kg}$ (vacuum 7 (28\%), forceps $5(20 \%)$ ). Most of the babies had more than 7 at APGAR 1 minute (vacuum $=72 \%$, forceps $=68 \%$ ) and at APGAR 5 minutes (vacuum $=100 \%$ and forceps $=96 \%$ ).

\section{DISCUSSION}

The most common age group in our study was 21-25 years in both groups (vacuum-48\%, forceps-52\%) followed by 26-30 years of age group (vaccum-32\%, forceps-24\%). Similar finding was also noted in Sonawane et al in his study done in Maharashtra were 21-25 years in both groups (vacuum-39\%, forceps-41\%). ${ }^{13}$ Similar findings also noted in Sharmila et al study where he noted 21-25 years (vacuum-48\%, forceps-52\%) followed by 26-30 years vacuum $10(20 \%)$, forceps $7(14 \%) .{ }^{12}$ It was considered by many authorities not to use vacuum for less than 34 weeks of gestation due to increased risk of cephalhaematoma.

The most common indication for instrumental delivery was delayed second stage labour (36\%) followed by fetal distress $(32 \%)$ and poor maternal effort $24 \%$ in forceps. The most common indication for vacuum was poor maternal effort $(52 \%)$ followed by delayed second stage labour $(36 \%)$ followed by fetal distress (4\%). Anurag et al showed that both the instrumental vaginal delivery (vacuum and forceps) common indication was delayed second stage (32\%) followed by fetal distress $(26 \%)$. We all knew that the prolonged second stage labour may lead to serious maternal complications and deaths and may also results in still births ,neonatal morbidity and mortality. ${ }^{14}$ In Gebre et al study he stated that cutting second stage of labour was an ideal option which was independent of indications of maternal and foetal in early studies which stated that the risk of fetal morbidity was higher if the hypertension and heart second stage of the labour extended for two hours. ${ }^{15}$

The most common complication in maternal morbidity was episiotomy extension (64\%) followed by first degree and second degree perineal tear $(44 \%)$ in turn by third and fourth perineal tear $(24 \%)$ in forceps delivery. In contrast to it, in vacuum delivery the first and second degree perineal tear $(32 \%)$ followed by episiotomy extension $(24 \%)$ in turn by blood transfusion (20\%). In Anurag et al cervical laceration (15\%) followed by $\mathrm{PPH}$ requiring blood transfusions (13\%), vaginal lacerations (10\%) and then by extension of episiotomy $(5 \%)$ in vacuum delivery and the most common complication was $\mathrm{PPH}$ requiring blood transfusion (18\%), cervical lacerations (14\%) followed by vaginal lacerations $(13 \%)$. Perineal trauma and neonatal injury was more in forceps whereas cephalhematoma was more in vacuum birth. In Biru et al study, forceps delivery mothers had more complications than vacuum delivery. ${ }^{16,17}$

The maternal morbidity was significantly less in vacuum compared to forceps. Similar results also noticed in Berna et al study which was a retrospective study done for a period 12 months January 2016-December 2016 Istanbul which stated that vacuum associated with lower caesarean section rate, lower usage of anaesthesia both regional and general and less pain at delivery and less maternal injury compared to forceps. In our study the neonatal morbidity was similar between infants delivered by vacuum or 
forceps whereas different rates of neonatal morbidity occurs in different literatures. In Rhiddima et al study, it was stated that the neonatal morbidity was lesser in vacuum compared to forceps. ${ }^{11}$ Multiple studies stated that there was a higher incidence of neonatal trauma in forceps compared to vacuum.

In our study, the APGAR score at 1 minute and 5 minutes were more than 7 whereas many studies also documented that the rate of neonates with APGAR score $\leq 3$ at 1 minute and was significantly higher after forceps compared with vacuum delivery but the difference was not statistically significant. Vacuum should be considered first in operative vaginal deliveries to reduce maternal injuries.

\section{CONCLUSION}

Our study concluded that vacuum significantly reduces maternal trauma than forceps and no difference noted in neonatal outcome. To reduce maternal injuries, vacuum should be considered first in operative vaginal deliveries. The major role was played by the operator rather than the instrument. Both forceps and vacuum assisted deliveries reduces caesarean section rate to $10-15 \%$ as per WHO recommendations. Proper training, timing, clinical skills are important for a successful instrument assisted deliveries. And this should be a part of training curriculum for all budding obstetricians.

\section{ACKNOWLEDGMENTS}

The authors like to thank the dean and medical superintendent, VMKV medical college, Salem.

Funding: No funding sources

Conflict of interest: None declared

Ethical approval: The study was approved by the Institutional Ethics Committee

\section{REFERENCES}

1. Hubena Z, Workneh A, Siraneh Y. Prevalence and outcome of operative vaginal delivery among mothers who gave birth at Jimma university medical center, Southwest Ethiopia. J Pregnancy. 2018;2018:7423475.

2. Murphy DJ, Strachan BK, Bahl R, Royal College of Obstetricians Gynaecologists. Assisted Vaginal Birth. BJOG. 2020;127:70-112.

3. Uptodate. Fact sheet: Operative vaginal delivery. Available http://www.uptodate.com/contents/operative-vaginaldelivery. Accessed on 10 September 2021.

4. Healthline. Fact sheet: Forceps versus vacuum. Available at: https://www.healthline.com/health/ pregnancy/assisted-delivery-forceps-vacuum. Accessed on 10 September 2021.

5. Jeon J, Na S. Vacuum extraction vaginal delivery: current trend and safety. Obstet Gynecol Sci. 2017;60(6):499-505.

6. Muraca GM, Sabr Y, Brant R, Cundiff GW, Joseph KS. Temporal and regional variations in operative vaginal delivery in canada by pelvic station, 2004-2012. J Obstetr Gynaecol. 2016;38(7):627-35.

7. Feeley C, Crossland N, Betran AP, Weeks A, Downe S, Kingdon C. Training and expertise in undertaking assisted vaginal delivery (AVD): a mixed methods systematic review of practitioners views and experiences. Reprod Health. 2021;18(1):92.

8. Singh S, Munikrishna M, Sheela SR. A comparative study of maternal outcome between vaccum extraction and outlet forceps delivery. Int J Reproduct Contracept Obstetr Gynaecol. 2018;7(6).

9. Liabsuetrakul T, Choobun T, Peeyananjarassri K, Islam QM. Antibiotic prophylaxis for operative vaginal delivery. Coch Datab Systemat Rev. 2017;8:004455.

10. Muraca GM, Sabr Y, Lisonkova S, Scoll A, Brant R, Cundiff GW. Morbidity and mortality associated with forceps and vaccum delivery at outlet, low and midpelvic station. J Obstetr Gynaecol. 2019;41(3):327-37.

11. Shetty R, Rajaratnam A. Immediate maternal and neonatal effects of forceps and vaccum-assisted deliveries. Indian J Obstetr Gynaecol. 2018;6(5).

12. Sharmila G, Sindhuri GK. A prospective study of immediate maternal and neonatal effects of forceps and vacuum assisted deliveries. IAIM. 2016;3(12):1-10.

13. Sonawane AA, Gadappa SN, Gaikwad RA. Study of feto maternal outcome in instrumental vaginal deliveries at a tertiary teaching hospital. New Indian $\mathrm{J} O b$ Gyn. 2021;7(2).

14. Wang L, Wang H, Jia L, Qing W, Li F, Zhou J. The impact of stage of labor on adverse maternal and neonatal outcomes in multiparous women: a retrospective cohort study. BMC Pregnancy Childbirth. 2020;20(1):596.

15. Gebre $S$, Hailu A. Complications of instrumental vaginal deliveries and associated factors in Suhul general hospital, Shire, North-West Tigray, Ethiopia. J Gen Pract. 2017;5:300.

16. Biru S, Addisu D, Kassa S, Animen S. Maternal complication related to instrumental delivery at Felege Hiwot specialized hospital, Northwest Ethiopia: a retrospective cross-sectional study. BMC Res Notes. 2019;12(1):482.

17. Chaudhari P, Bansal N, Gupta V, Tandon A, Chaudhry A. A comparative study of feto-maternal outcome in instrumental vaginal delivery at tertiary health level hospital in Uttarakhand state. Int J Reprod Contracept Obstet Gynecol. 2016;5(6):3294-9.

Cite this article as: Jeyamani B, Dhasleema AN. Fetomaternal outcome in operative vaginal delivery. Int J Reprod Contracept Obstet Gynecol 2021;10: 4096-100. 